The Quarterly Journal of Austrian Economics

Volume 22 | NO.3 | 357-382 | FALl 2019 WWw.QJAE.ORG

\title{
INTRA-FIRM COORDINATION THROUGH Rule-Following AND THE EMERGENCE OF HIERARCHY
}

\author{
Aidan Walsh and Malcolm Brady*
}

JeL Classification: B53, D23, D83, L22, L26, M14

Aвstract: Rules and rule-following are becoming better understood as decision-making and coordination mechanisms. Further, that hierarchy is an under-appreciated element of natural spontaneous, rule-based, orders has caused confusion. The article argues firstly that the ability to meld rule-following and hierarchy in one theory of the firm presents an opportunity for a possible consistent Austrian theory of the firm. The paper then proceeds to discuss how rule-following is embedded in conventional theories of the firm and how a rule-based firm can create value in the larger spontaneous order of the extended market. The paper concludes by arguing that even though conventional views around hierarchy and the giving of orders within a firm may have a role, the conventional view may be under-privileging the role of rules, rule-following and the consequent natural emergence of hierarchy.

"The enemies of liberty have always based their arguments on the contention that order in human affairs requires that some should give orders and others obey" (Hayek 1960, 159).

"We may only learn from the necessity of rules, wherever men have intercourse with each other" (Hume 1751, 38).

"Aidan Walsh (aidan.walsh@ie.ey.com) is tax partner with EY, Dublin, Ireland. Malcolm Brady (malcolm.brady@dcu.ie) is associate professor at Dublin City University Business School. 


\section{INTRODUCTION}

$\mathrm{T} t$ is a universal feature of firms that they are hierarchical 1 (Williamson 2009). Every firm, no matter how egalitarian, has a 'boss'; even in Koch's (2007, 130, 133) market-based management some individuals have more 'decision-rights' than others. It is a common view that firms are hierarchical in order to facilitate the flow of 'orders' and 'commands'; hierarchy is equated to authority which inevitably is exercised through commands or orders (Schlicht 1998, 220).

The essential nature of command in conventional theories of the firm is clear from Coase's seminal essay on the firm: “... the distinguishing mark of the firm is the supersession of the price mechanism..." (Coase 1988, 36, 38); he goes on to give a command as an example of such a supersession: an employee moving from department $Y$ to department $X$ "because he is ordered to do so" (Coase 1988, 35). This view of firms as command led hierarchies is strongly held because it is so intuitive.

The purpose of this article is to challenge this view that command is essential to the nature of the firm, to argue that we have misunderstood hierarchy and that rule-following, i.e. uncommanded, behaviour, may be a more important coordination mechanism for intra-firm activities than is generally recognised.

The article is divided into four parts. The first part looks at the emerging literature on hierarchy in naturally occurring spontaneous orders. The second part looks at the Austrian literature on the firm and the role of 'command' and 'rule following' in that literature and shows how understanding hierarchy as a natural feature of spontaneous orders resolves some difficulties in that literature. The third part looks at the conventional literature on the firm where rule-following has been a feature but where there is still recourse to command as being viewed as the primary coordination mechanism. The fourth section of the article argues that intra-firm coordination through rule-following extends the problem-solving power of the extended market order and allows different firms to create value in the larger market order in different ways. The paper concludes by suggesting that the role of rule-following within the firm has been under-appreciated and under-privileged. 


\section{Hierarchy is a feature of natural spontaneous orders - an unexpected development.}

One of the difficulties for Austrian theorists of the firm is a general belief that spontaneous rule-bound orders are not hierarchical (Pongracic 2009, 92). This is not necessarily correct.

It is now generally agreed that rules are the foundation of coordinated behavior in animals (Hayek 1967, 66; Miller 2010, 175; Quera, Beltran, and Dolado 2010). With no leaders or external factors, order can emerge naturally from independent agents following common rules, the classic example being Reynolds's flocking 'boids' (Reynolds 1987; Miller 2010, 174). However, Reynold's simple computer program, where 'boids' following simple rules (fly at the same velocity as nearby birds, stay close to nearby birds, but avoid collisions) resulted in flocking-like behavior, has in some ways led us astray. As has Hayek's focus on spontaneous orders where unthinking objects, iron-filings etc., are the basis of spontaneous orders (Hayek 1973, 40, 43).

Recent research has shown that flocking and herding rules include taking cues from 'leaders' and decision-makers, such as more experienced homing pigeons (Flack et al. 2012). Leaders have been observed to emerge within flocks of pigeons: 'we found that stable, hierarchical pattern of in-flight leadership does not build upon the stable hierarchical social dominance structure evident in the same birds. Instead, in the case of pigeon flocks, the emergence of leadership and dominance hierarchies are each affected by different factors. By ignoring social dominance when in flight, flocks of pigeons potentially make better navigational decisions because leadership can emerge from relevant attributes, such as local experience and route fidelity' (Nagy et al. 2013). Even tiny stickleback fish exhibit differences in behavior which drives leadership which results in particular forms of emergent shoal behavior (Jolles et al. 2017). ${ }^{1}$

${ }^{1}$ With an almost Austrian emphasis on the diversity of abilities, Jolles et al. write:

In recent years it has become apparent that across a wide range of animal taxa, individuals commonly differ consistently from one another in their behaviour ('animal personalities'), often with large fitness consequences and wide-ranging ecological and evolutionary implications. Such variations could provide a level of heterogeneity within animal groups that may drive 
According to Biro, "every [homing] pigeon has their own opinion on how to get home" (Biro 2016). Every homing pigeon is obviously committed to getting home but they will be guided, to some degree, by more experienced pigeons, better navigators and, of course, staying in the flock has advantages that outweigh acceptable deviations from a preferred course home. But sometimes the leader is wrong and the other pigeons will ignore him or her (Watts et al. 2016). Further, the flock will not follow the same route home that the leader would follow if flying solo-showing that the leader is influenced by the flock (Pettit et al. 2015).

Hierarchy is also a natural feature of human spontaneous orders. In the market order, participants will be influenced by (or it could appear, "follow the commands" given by) other market participants like Warren Buffett. The anthropologist E.E. EvansPritchard described the Nuer in the Sudan in the 1930s; he noted that their society was extremely egalitarian but that forms of hierarchy also existed:

\begin{abstract}
The ordered anarchy in which they live accords well with their character, for it is impossible to live among Nuer and conceive of rulers ruling over them.... Wealth makes no difference... Birth makes no difference... [But] The words of some elders count for more than the words of others... Leadership in a local community consists of an influential man deciding to do something and the people of other hamlets following suit at their convenience" (Evans-Pritchard 1940, 179-81).
\end{abstract}

Another example would be the common-law legal system, an example given by Hayek of a spontaneous order (Hayek 1973, 81, 86). Here, again, hierarchy naturally emerges, with judges making decisions at various levels until there was an ultimate arbiter at the apex of this hierarchy-a king, a group of bishops and now supreme courts.

It is therefore not inconsistent even with pure spontaneous orders for there to be a hierarchical element. This hierarchical element

collective behaviour. Indeed recent studies have started to provide support for that notion and have shown that consistent behavioural differences can influence leadership, social network structure, collective dynamics and group performance.... Relatively simple interaction rules play an important role in the emergence of collective behaviour.... (Jolles et al. 2017) 
may also be a feature of the larger market order but in a much less visible way. We may not feel that Warren Buffett is our superior, but we may avidly read his annual letter to investors and follow his advice just the same; we may not have a 'boss' in our market based activities but we may be a slave of some market or trend influencer, the economics of Snapchat or Instagram may have made this much clearer to us all. This also makes clearer how entrepreneurs play a leadership role, in, in Kirzner's phrase (p. 18), the "mutual learning" that is the essence of the market process.

Further, we embed ourselves in the rules of different rule-based orders all the time, as employees, as customers, as suppliers and owners. For example, we will behave quite differently in a fast-food restaurant than in a fancy expensive one; we would not dream of clearing our own table in a white-linen restaurant but would 'automatically' in a burger joint. This is not us accepting 'commands' from a hierarchy, we have not fleetingly become employees as we empty our tray, but evidence of our innate ability to switch from one set of rules to another usually without conscious effort. The maître d' may tell us what wine goes with what dish but we do not follow his or her commands, we bow to his or her superior knowledge of fine dining.

This is not a command hierarchy; this is not a hierarchy with commands cascading down but individuals happy to be guided by the advice, decisions or actions of others, however, inarticulately barked out (Brady and Walsh 2008). This does not mean that individuals can not try to give a command, after all what is the point of humans being able to speak if we cannot shout instructions at each other? However, just because we can shout, does not necessarily mean that what we shout is an order or a command. As Mary Parker Follett put it: "I may say to an employee, 'Do so and so,' but I should say it only because we have both agreed, openly or tacitly, that that which I am ordering done is the best thing to be done. The order is then a symbol" (Follett 1941, 65) We can say the same of Coase's

\footnotetext{
${ }^{2}$ See Kline and Martin (1958) and Pongracic (2009, pp. 38, 39) for further examples. Kline and Martin (1958) is particularly interesting. Hayek quotes from it in The Constitution of Liberty $(1960,427, n$. 10) but only in relation to the loss of knowledge in relation to command. He makes no reference to the article's use of rules as the solution to the knowledge problem of authority. Indeed, it is not until the early 1960s that he publishes works specifically on rules and rule-following (outside of
} 
seminal 'order' that an employee should move from Department $X$ to Department $Y$ : is that a command or merely an inarticulate expression of the rule, if there is not enough work in Department $X$ at any particular point in time then go to Department $Y ?^{3}$

This insight, that hierarchy emerges naturally from rule-following within a group as individuals look to others with more experience, skills, more or better knowledge or information and better knowledge of the rules, has major implications for theories of the firm. Conventional theories of the firm are largely focused on this visible hierarchy and this has allowed them to starkly contrast the firm with the larger market order. Williamson in his

his prior interest in the rule of law) as decision and coordination mechanisms. The article may have been part, if uncited, of Hayek's realization of rules and rule-following as the basis for the classification system articulated in The Sensory Order that was then recast in rule terms in his writings in the 1960s (Hayek 1967, 43ff; Caldwell 2004, 296, 306, 307).

${ }^{3}$ Once we see that hierarchy is not inconsistent with rule-following, our eyes are opened to the possibility that many 'orders' that cascade down that hierarchy may not be commands at all; many instructions that individuals consider to be commands may be merely the articulation of a rule. Simon's (1991) example, "repair this hinge," can be rearticulated as a rule, ("If a hinge is broken, repair it") and a piece of information ("This hinge is broken"). Coase's example of a command (Coase 1988, 35), an employee moving from department $Y$ to department $X$ "because he is ordered to do so," can be reinterpreted as a rule: if Department $Y$ is quiet then move to Department X (Schlicht 1998, 222). Therefore, when there is an articulation of a rule or a piece of information ("Repair that hinge!") and the rule is followed, it can appear that this demonstrates the power of the command and of the commander. We recall that Hayek originally argued that very specific rules could end up being close ("shade gradually into") to command (Hayek 1960, 114, 148; Vanberg 1994, 266, n. 14). However, while this might look like the position when a command is compared to an isolated application of a rule (repair that hinge!) that cannot be the case generally: even the most specific rule like "if a room is dark, turn on the light," informs every situation where one is in a dark room and also allows for unexpected situations like there is no electricity and the light switch does not work and you could use your mobile phone as a light. This is completely different from a command: Turn on that light! This tells you nothing about any other room, any other light, or any other situation. You can disprove there is command in organizations by asking yourself if you told someone to move from Department $Y$ to Department $X$ and on some other day, when circumstances were similar, you saw the person in Department $Y$ and they said they were only there because noone had told them to go to Department X. You would be annoyed. Why? If they failed to follow a clearly articulated rule you would be right to be annoyed; if they were waiting until someone told them what to do then you should congratulate them on their understanding of the theoretical basis of intra-firm coordination. 
Nobel Memorial Prize-winning speech made this point explicitly contrasting the hierarchical firm with "spontaneous adaptations" in the market (Williamson 2009). In conventional theories of the firm, individuals in authority do not, obviously, have coercive powerthey cannot kill or imprison you if you do not follow orders. But they are thought to have power because leaders in organizations have control over the resources of the firm (Roberts 2004, 103). However, this argument is obviously circular and cannot explain how individuals lose power, how CEOs end up being sacked; in fact, Turner argues that causation is the exact opposite, individuals get control of resources because the group has conferred power on them (Turner 2005).

What we see when we look at our pigeons flying home is a powerful vindication of the early management theorist, Mary Parker Follett. Follett argued that there is no command within organization just individuals following the "law of the situation." She wrote: "The leader gets an order followed first, because men do really want to do things in the right way and he can show them that way, and secondly, because he too is obeying" (Follett 1941, 276). This seems so counterintuitive when we look at leaders in organizations barking out orders. But when we look at our pigeons flying in a coordinate flock, we cannot hear any commands, we cannot see any gestures, no pigeon has control of resources or any property at all but we do see hierarchy and leadership. But if we have discounted hierarchy in natural spontaneous orders because the leadership is largely invisible, have we over-privileged hierarchy in firms where leadership seems so visible and where the ability to secure coordination through being able to give orders and commands seems so clear?

This focus on hierarchy and the logical flaws in coordination through command and orders has been central to a dispute within Austrian theorists of the firm. We will explore this next.

\section{The illusory conflict within Austrian theories of the firm.}

In this section, we look at Austrian, effectively Hayekian influenced, theories of the firm. Hayek's starting point was to look at the difference between a command and a rule. A command "aims 
at a particular result or particular foreseen results, and together with the particular circumstances known to him who issues or receives the command will determine a particular action" (Hayek 1976, 14); a command, by definition, must not be in accordance with the rules, otherwise the 'command' is merely rule articulation. Coase's example given above meets Hayek's definition of command. Hayek contrasts a command with a rule. He suggests that a rule "merely states certain attributes which any such action ought to possess" (Hayek 1976, 14). For example: "If \{condition/situation\} A, do B" is a rule (Becker, 2004) as is "If A, B is forbidden." The complexity of the rules is somewhat overlooked in the simplicity of each individual rule; if $\mathrm{A}$ do $\mathrm{B}$ but if $\mathrm{A} 1$ do $\mathrm{B} 1$ or if $\mathrm{A} 2$ then do $\mathrm{B} 2$ can often require quite subtle thinking as to discover the correct situation, the correct rule or priorities of rules and to articulate the rule or the consequent action (Hayek 1967, 57).

Hayek's key insight into the knowledge problem of central planning (Hayek 1948, 33ff) was the starting point for much of his later work on how the market order solved this knowledge problem. As is well known, Hayek argued that rules and rule-following behavior provided for the solution; rules are used by individuals to make decisions despite their constitutional ignorance, and the larger market order is a spontaneous order created by individuals following common rules.

On the other hand, Hayek considered that organizations (taxis in Hayek's phrasing), as opposed to markets (cosmos), were coordinated by commands, but that there was also a role for rule-following. However, Hayek said that these rules of organization were a particular type of rule-rules, allowing the organization member to use some element of their knowledge, for the performance of assigned tasks to fill in the gaps in commands (Hayek 1973, 49; Vanberg 1994, 114). Generally, Austrian students of the firm are now agreed that Hayek, who "had little interest in organizations" (Foss and Klein, 2013), made unnecessary distinctions (with the larger market order) when he argued that organizations had to have a concrete goal ${ }^{4}$ (Vanberg 1994, 142) and where he argued that the

\footnotetext{
${ }^{4}$ In some cases at least it may be an example of the post hoc ergo propter hoc fallacy applied to the theory of the firm. Barnard, himself, gave an example of this in a letter of 6 January 1956 to Hayek:
} 
rules were necessarily subordinate to the command in an organization - in fact the opposite may have to be true (Ioannidis 2003a).

Despite this, Austrian economists have sought to apply Hayek's knowledge problem and its solution to internal coordination within the firm. And the more recent Austrian focus on entrepreneurship and uncertainty has given us real insight into the limitations in the knowledge of entrepreneurs and managers; there is a knowledge problem not just within the larger market order but also within firms. Ioannides writes: “....the promotion of the entrepreneur's business conception requires the information absorption capacity, the creativity and the problem solving capability of firm members. All these capabilities presuppose that the individual member acts within a framework of sufficiently abstract rules ... In other words, the firm cannot but, at the same time, must not operate on the basis of commands" (Ioannides 2003b). "Cognitive constraints prevent the entrepreneur, as much as anyone else, from imaging all possible moves that unfold in the future" (Witt 2007).

However, despite these commonalities in the Austrian literature on the firm, there are now two quite different lines of thought on the role of hierarchy in intra-firm coordination: one line, taking a realistic view of the internal workings of the firm, notes the universal existence of hierarchies within firms and argues that this must result for some role for 'command' within the firm (Foss and Klein, 2013); we can call this the 'realism' line of thought. The other line focuses on the knowledge problem in any kind of central direction and proposes

Based upon my experience and observation I had arrived at conclusions consistent with yours before I had read any of your work or had heard of Michael Polanyi whose analysis of the situation [in The Logic of Liberty], I think, is correct and very valuable, but it is not sufficient. It seems to me that one has to be able to explain the illusion of successful planning.... In this city [New York] and its environment, in which there are millions of telephones, it is possible with almost complete certainty to make anyone of millions of possible connections merely by dialling correctly. The extreme degree of coordination of electrical and mechanical details to make this possible is almost incredible and an enormous amount of engineering work has gone into it and there is a blue print for nearly inch of the property concerned. It certainly looks as if the system as a whole has been meticulously planned to be what it is [by the New York Telephone Company]. Yet, this is absolutely false, as a whole it never was and never could have been planned (Barnard, F.A. Hayek papers, 1956). 
market-process type solutions like rule-following; we can call this the 'logical' Austrian line of thinking on the firm (Langlois 1995).

The realism line argues that rule-following is an important coordination mechanism within the firm, but that this does not affect the essential role of authority, hierarchy (Sautet 2000, 98) and the ability to give 'orders' and 'commands': that managers can get things done by merely telling people to do it. This line in the literature argues that the role of rules fluctuates in line with the degree of uncertainty and the amount of knowledge of the employees that must be used-the paradigm example being a new entrepreneurial firm with knowledgeable employees and a boss with cognitive and knowledge limits (Ioannidis 2003a, Witt 2007).

But despite what should be a natural antipathy to 'command', the Austrian perspective on the firm constantly returns to the obvious existence of hierarchy and, as they take it, its inevitable consequent coordination mechanism: command. Foss and Klein argue that command is essential to firm purpose. While they note that "knowledge causes authority (as a centralized decision-making system) to fail in all its forms" (Grandori 2002) they also write that: "consistent (or heavy-handed) application of Hayek's decentralized argument leads to an apparent absurdity: if decentralization always and everywhere improves the utilization of dispersed knowledge, it would be hard to find any rooms [sic] for firms, and certainly for contemporary mega-sized firms... Yet (large) firms exist" (Foss and Klein 2013). Pongracic makes the same point: “...it should be obvious that most successful firms engage in some form of command-and-control, hierarchical operations. It seems highly unlikely that all these multitudes of entrepreneurs have been doing it wrong all along!" (Pongracic, 2009, p. 43).

The overall result of this stream in the literature is that the business firm is a "hybrid Hayekian order" (Ioannidis 2003a) partly coordinated by rules and partly by command (in Hayekian terminology, neither a 'cosmos' nor a 'taxis') — with the mechanism mix fluctuating from firm to firm. Unfortunately, and paradoxically, as Pongragic has noted $(2009,72 \mathrm{ff})$, this point that firms do not or should not emulate the larger market order, has morphed into an Austrian emphasis on the importance of hierarchy, authority and command (Cowen and Parker 1997, 75). 
The second line of thought, building up logically from Austrian insights into market processes, also looks to rule following but is more sceptical of the power or abilities of hierarchy. The most direct application of that thinking is to argue that markets should be brought within the firm to solve the inherent knowledge problem with intra-firm coordination (Cowen and Parker 1997, Koch 2007). But if the problem was that simple to solve, why would firms have emerged at all? And, sure enough, we find, within for example the Koch companies which apply this market-process approach, all kinds of rules, like formal "decision rights" (Koch 2007, 126), that do not exist in that way within the market order.

Langlois argues that firms cannot plan in the conventional sense but instead must emulate to some degree a spontaneous order (Langlois 1995). Langlois draws on business history to demonstrate that firms move, in some form of coordinated way, from business to business without, inevitably given cognitive constraints and uncertainty, having a clear idea what they are doing but still being able to do it. But Langlois's solution of firms relying on abstract rules to navigate this uncertain future also resulted in Langlois being "sceptical of hierarchy." More recently Bylund (2016) takes a similar market process approach and comes to an even stronger conclusion: "we commonly perceive the firm as a hierarchy and that we as employees 'follow orders' from higher-ups in the workplace. But this perception is unfounded.... There is no reason to perceive of the firm as a hierarchy. Indeed we find no basis for authority...." (Bylund 2016, 88, 95).

Emerging in the Austrian literature of the firm are two different approaches to the firm-the logical approach that relies on the market process and denies that an authority relationship can exist, or is even desirable, and a realism school that argues that hierarchies are an observable feature of firms and so must have some function.

However, it is possible to square this logical-realism circle. If we appreciate that hierarchy can be a feature of rule-following orders, in fact that hierarchy can emerge naturally within any group of sentient rule-following agents, then we can see how an Austrian focus on rules, rule-following, uncertainty and cognitive constraints can be consistent with hierarchy. Especially, when we appreciate Follett's point that many articulated commands or orders may be merely rule articulation. 
On the other hand there is no need for acute observers of the firm like Langlois, to be "sceptical" of authority or hierarchy. The power of a spontaneous order to deal with the Hayekian knowledge-problem is not diluted by a hierarchical element that, in fact, may be an emergent feature of all spontaneous orders created by sentient agents following common rules.

\section{Rules and conventional theories of the firm.}

This insight in allowing us to integrate the different schools with the Austrian literature on the firm, by allowing for hierarchy to emerge naturally as a consequence of rule-following, also allows us to integrate the Austrian focus on rule-following with the more conventional literature on the firm as well.

Rules have become more central in general discussions about decision-making. In Risk, Uncertainty and Profit, Frank Knight noted that we all act in an environment of change and uncertainty: the problem of life is that we know so little and yet we manage to act. He argued that the manager in a business firm solves this problem through a process of 'trained instinct', 'judgment' or 'intuition' (Knight, 1921, pp. 211, 223); in other words he knew these decisions were made but had very little idea how they were made. Modern research in psychology and economics on how individuals make decisions has given us insights into the foundation of that 'intuition'. We now know that individuals make judgments and decisions, not by elaborately generating and ranking options, but by following 'heuristics' i.e. rules. It is clear that this is also true for decisions made within business organizations. According to Kahneman, ' $[\mathrm{w}]$ hatever else it produces, an organization is a factory that manufactures judgments and decisions' (Kahneman, 2011, p. 418).

So we would expect the entrepreneur to attempt to coordinate through rule-following; articulated as such or not. An example of one entrepreneur using rules is when Henry Ford started the process of creating his "universal car;" he was trying to coordinate the activities of a number of individuals but without being able to articulate any concrete objective: "The plan which I then had in the back of my head but to which were then [1904] not sufficiently advanced to give expression...." (Ford and Crowther 1923, 56, 57). 
But even at that early stage Ford could articulate clear rules, from which the design of his car, he hoped but could not be sure, would emerge: "The universal car had to have these attributes: (1) Quality in material to give service in use; (2) Simplicity in operation-because the masses are not mechanics; (3) Power in sufficient quantity... (4) Absolute reliability...."

However, these insights into the power of rule-following have been missed because the emphasis on rule-following in the conventional literature on the firm had a different starting point and so a different focus. Max Weber in his writings about bureaucracy, and the rules that bureaucrats followed, wrote about the "regular," "stable," "methodical" characteristics of the modern bureaucracy (Weber 1968, 956). This early focus on rules in organizational studies has skewed the understanding of rules and rule-following in organizational theory and economic theories of the firm which have become focused on rules in routine situations (Becker 2004, Nelson and Winter 1982); 'rules' became synonymous with 'rigidity.'

However, despite the "tendency for authors to slide between 'rules' and 'routines'" (Loasby 2000), rules, more recent studies have shown, can also guide decisions in non-routine, novel or uncertain situations also (Gigerenzer and Gassmaier 2011, Gigerenzer 2007, Klein 1998, March 1997). Again, the conventional view has been inverted-it is following rules that provides for flexibility and following commands that is necessarily rigid. That rule-following allows for fast decision-making and that these quick decisions can be useful is a new development (Kahneman 2011). Eisenhardt and Sull (2001) make the point that rules are an appropriate coordination mechanism in "rapidly changing, ambiguous markets" where strategies are "constantly evolving." Looking at actual company strategies, and without referring to any underlying theory or to management history, the authors had noticed the pervasiveness of rules in strategy formulation, articulation, and coordination. ${ }^{5}$

\footnotetext{
${ }^{5}$ What is less well-known is recourse by the military to similar rules-based instruction. Arrow argued that (Arrow 1974, 68): 'The purest exemplar of the value of authority is the military.... Under conditions of widely dispersed information and the need for speed in decisions, authoritative control at the tactical level is essential for success' (p. 69). And that putting in place rules for every eventuality is "highly costly." This is a point repeated most recently by Foss and Klein $(2012,216)$.
} 
If we take these insights into rule-following within the firm and apply them to existing theories of the firm we can see that many are writing about rule-following but, as with Knight, are struggling to articulate their insights in a clear way. Many existing theories are based on rules and rule-following behavior: routines (which are just rules to deal with regularly occurring situations) (Becker 2004, Nelson and Winter 1982), capabilities (the ability to make

Contrary to expectations, the military and other military-like organizations such as the fire services, police and coast guard, do not rely on command even in non-routine circumstances (Klein 1998); even though senior military figures have the ultimate coercive power to make their soldiers do exactly what they want, they do not use it. These are the orders that the great Prussian general Moltke made at the outset of Prussia's war with Austria in 1866 to the commanders of Prussia's First and Second Armies, who within weeks would crush the Austrian army between them:

.... With regards to distance, road connections and railroad, the direction [i.e. not a specific location] of Gitschin has been designated for eventual junction of both armies.

By this it is not of course meant that the point must be reached under any and all circumstances, because that will depend entirely on the course of events ... [However] the convergence of all our armies for the main decision must always be kept in view (Moltke 1993, 245).

Moltke's orders can be easily expressed as rules: if there is a choice over direction, then choose the direction of Gitschin; if there is a choice between convergence and divergence with the other Army, then choose convergence; if there is a choice between direction and convergence, then choose convergence. (Note how there is no concrete goal.) The German army's Field Service Regulations, dating back at least as far as 1887 (Samuels 2013) are almost Hayekian: "Every individual from the highest commander to the lowest private must always remember that inaction and neglect of opportunities will warrant more severe censure than an error of judgement in the action taken" (Halder et al. 1953, 7, 8; Creveld 1982). Articulated orders in this system were designed to give context and decision support premises to each individual soldier, so that when faced with the unexpected they knew what to do in a way that was coordinated with the rest of the soldiers in the army (Bungay 2011). This is the basis of current US Army military doctrine (United States Command and General Staff College 2014, 54). In developing his theories Hayek himself may have drawn on his own military experience: "his experience of the retreat [with the Austrian Army from the Piave River in Italy in 1918] first got Hayek thinking about spontaneous orders - the soldiers had no central direction, yet the retreat was more or less orderly" (Caldwell 2004, 135 n. 3; Leube 2003). This, of course, we now realize does not mean that the groups of men and boys were without leadership, there must have been individuals who had more local knowledge, better ability to find food etc. who would have emerged in the retreat. 
superior coordinated decisions, i.e., rule-following) (Loasby 1998), contractual relationships (that is, rule-bound relationships) with incentives for and monitoring of adherence to the rules (Alchian and Demsetz 1972), even hierarchies and authority (Williamson 2009, Coase 1988) (See Walker [2015] for a useful review).

But each theory has to introduce an artificial element that could be seen to fall away if a greater emphasis was given to rule-following. For example, if we look at Alchian and Demsetz's paper, their logic, as Austrian writers on the firm have repeatedly pointed out, is impeccable: the employment relationship is just another market transaction, the employer has no more ability to 'command' the employee than the customer his or her grocer. However, to give their insight more realism, the authors introduced a centralized element:

\footnotetext{
... a special class of contracts.... Instead of multilateral contracts among all the joint inputs' owners, a central common party to a set of bilateral contracts facilitates efficient organization of the joint inguts [sic] in team production.... We conclude with a highly conjectural but possibly significant interpretation... the firm can be considered a privately owned market....
}

They talk of the firm as a form of "specialised surrogate for a market" at the center of a nexus of contractual relationships with the firm as the central contractual hub. Rearticulating that description of the firm as a unique rule-bound order, with employees committing to following the rules, and agreeing to being sanctioned or excluded if they fail to follow them, eliminates the cumbersome, and completely artificial, requirement to have a complex system of everchanging contractual relationships with a legal fiction as nexus. The requirement is now merely to follow different rules to the larger market order. This goes to the core of their analogy between the employee/employer relationship and the customer/grocer: as you wander around the grocery store looking for tins of tuna, you do not have, yet, any contractual relationship with your grocer-you have a market order in which you both will follow rules and within which you can predict each other's behavior. Similarly, within a firm, the employees do not need a contractual relationship with each other or with a common artificial nexus. All they need are common rules and a mutual commitment to follow them. At the same time, the emergent feature of hierarchy within rule-following 
orders allows us to answer the most common criticism of Alchian and Demsetz's article that there is a hierarchy within the firm but none in the larger market order. As we have pointed out rule-following within the larger market order and identical coordination mechanisms within the firm may result in more visible hierarchies in the latter than in the former but the mechanism is still the same.

Alghion and Tirole (1997) give a realistic view of the firm where decisions are delegated but they can only see this delegation as involving "a costly loss of control for" the superior. And they have no mechanism to explain how delegated decision can be coordinated; they very much imply they cannot and so only "relatively unimportant" decisions can be delegated. Again, a rule-following perspective from the Austrian literature would show how delegation exists within a hierarchy, both the hierarchy and the delegation are natural consequences of rule following, and how rule-following results in actions that can still be controlled and coordinated even in urgent and unforeseen circumstances.

\section{Rules and 'Culture'}

Hayek's work on rules was an early example of an increasing focus on rule following in human behavior and coordination. It has become clear that rules are central to all human activities. Dopfer writes that "Homo sapiens can thus be viewed more generally as a rule-making and rule-using animal" (Dopfer 2004). But rules and rule-following are especially important in institutional settings. Social institutions are "nothing more than agents rationally following rules of action, and being believed by other agents to do so" (Rowe 1989, 5). Other authors note the usefulness of rules in coordinating behavior generally (Heiner 1983) and specifically within firms (Grant 1996). However, in many ways the conventional literature on firms and management is merely catching up earlier theorists, like Follett, and practitioners, like Henry Ford.

A neglected subject, however, is the interaction of rules with 'orders' and 'commands' in an institutional setting. A command is, by definition (Hayek 1973, 97, 99; Vanberg 1994, 129; Polanyi 1951, 141; Hayek 1976, 20), outside of any rule-system. If we return to Coase's example of a command: an employee is told to move from 
Department $Y$ to Department $X$ because "he is ordered to do so." The employee must think: is this a command or a rule (Schlicht 1998, 232)? Do I go to Department X just this once or every time or times when the factual situation is similar (like there is no work to do in Department X)? Without such clarification, there is a risk that an employee mistakes a rule for a command or vice versa-i.e. repeatedly carrying out an action where the original instruction was actually a once-off command but the employee thought it was rule-articulation. This is not a source of error that is identified or discussed in the literature, or even much in real life. Why is that? Perhaps because rule following and its hierarchical consequences are more pervasive than we thought?

Chester Barnard noted an "authority paradox" within organizations: activity is coordinated within firms even though we do not do as we are told. In Barnard's words, "It is surprising how much that in theory is authoritative, in the best of organizations lacks authority - or, in plain language, how generally orders are disobeyed" $(1938,161,162)$. However, understanding rules as the coordination mechanism within the firm easily allows us to resolve this paradox, as Barnard did: 'orders' are not followed where they conflict with the rules (maybe the wrong rule was articulated or maybe circumstances have changed and a different rule should be applied now), and thus, despite orders being disobeyed there is no loss of coordination. In fact, coordination is sustained only because 'orders' are disobeyed and this is why, as Barnard pointed out, “... obvious disobedience [is] carefully disregarded" (p. 162).

This feature of corporate life, that things continue in their own way despite the frantic efforts of senior management, is often identified as 'corporate culture'; Hayek defined 'culture' as "the rules of conduct which govern the structure and functioning" of groups of people (Hayek 1978, 156) - "the brain is an organ enabling us to absorb but not to design culture." What is now clear to everyone is that every company has its own unique corporate culture; in Schlicht's vivid phrase: "Anthropologists may travel from island to island and observe that each harbours people with a particular custom. It is not necessary to go that far away, however. In modern economics, each firm forms an island of custom in the ocean of the market" (Schlicht 1998, 207). And the number of potential islands appears to be almost infinite; Vanberg $(1994,78)$ points out: the 
"cultural rules ... appear to be exceptionally variable and it is the variability of these rules that accounts for the diversity of social orders." We can thus explain why there can be an infinite number of different 'corporate cultures' in the larger market order, but what is not so clear is: what problem is that solving and what value does a firm extract from having a different culture to every other firm?

In much of management literature this culture thwarts and frustrates the efforts of leaders and management; Roberts refers to it as an "inert" element $(2004,28)$. What is also clear is that this culture is not completely 'created' by the firm founder or leading entrepreneur; even in the smallest firms, of only two or three people, the founder can feel that "control... slips away" (Ruef 2010); as early as 1980 Apple was making decisions that Steve Wozniak, one of the founders, did not understand or "like one bit" (Wozniak and Smith 2006, 230). A firm is not a "designed order;" as Ruef has pointed out: "Entrepreneurs... are defined by their intention to form a social group" (Ruef 2010, 7). Any social group is beyond the ability of any one person to create or concretely manipulate (Hayek 1952, 71).

The firm retains coordination, despite 'orders' being disobeyed and despite control, even knowledge of the current rules, slipping away from the founders, because the rules of the order are being adhered to- or as it is put colloquially, "culture eats strategy for breakfast"! (Groysberg, Price, Lee, and Cheng 2018).

However, the purpose of this article is to argue that this culture is not a by-product or even an unfortunate complication of firm creation but instead may be regarded as the essence of the firm-the rule-bound order, the 'culture' in other words, is the firm and that those rules, that culture, is different from every other firm is both inevitable and potentially valuable. The basic premise of anthropology is that every culture sees the world in a different way; in the words of Engelke, anthropology is "a way of seeing things, a way of thinking. Culture is a way of making sense" (Engelke 2017, 31, 32). Within organizations, culture has been defined as having a coordination role: the "social or normative glue that holds an organization together" (Smircich 1983), and a decision-making role, as Casson has pointed out: "'Learning by doing' is an important aspect of problem solving and so learning effects will give each culture a distinctive type of problem-solving expertise" (Casson 1995, 89). In 
other words, we have described rules following in terms of 'If A, then $\mathrm{B}^{\prime}$ but the rules also tell you which ' $\mathrm{A}$ ' to pay attention to in the infinite number of potential problems that might be solved.

Perhaps an example may help. Steve Wozniak designed the Apple I and the Apple II and was clear on this from the start that he wanted to build a cheap computer. He worked as an employee of $\mathrm{HP}$ when he designed those computers-yet he did not feel he was competing with HP's personal computer "[i]t wasn't like ours-it was aimed at scientists and engineers and it was really expensive.... How could HP [build a cheap computer]? It couldn't" (Wozniak and Smith 2006, 175, 176). He founded Apple Computers in 1975 with Steve Jobs and Ron Wayne and but even Wozniak initially thought of his machine of hobbyists and not for "regular people in regular homes" - this came later (p. 197).

In late 1979 Steve Jobs was given access to the Xerox research center, PARC. During that tour, an engineer, Larry Tesler, gave him a demonstration of a 'mouse' and a graphical user interface. Malcolm Gladwell describes what happened: “Tesler recalled. "He was very excited. Then, when he began seeing the things I could do onscreen, he watched for about a minute and started jumping around the room, shouting, 'Why aren't you doing anything with this? This is the greatest thing. This is revolutionary!'” (Gladwell 2011). It is one of the most celebrated moments in modern business history and Xerox is widely derided for not having exploited this intellectual property and instead, effectively, giving it away to Apple. But, as Gladwell points out, Xerox and Apple saw the problem in different ways: "PARC was building a personal computer. Apple wanted to build a popular computer."

What was obvious to Jobs and employees in Apple was not at all obvious to employees in Xerox or HP; as Yu points out rules facilitate decision-making by limiting our choices (Yu 2005, 9)—for Xerox or HP, building a consumer or popular product was not within its realm of choices. For an employee in Xerox, focused on business customers, a mouse was a way of making technicians more efficient; for Jobs and other individuals in Apple it was a way of making everyone a computer technician; the same $\mathrm{A}$ but for Apple-If A then B and for Xerox If A then C. Apple in 2018 reached a market value of over $\$ 1$ trillion but Xerox still has a market 
capitalization of over $\$ 6$ billion; with different rules Xerox might have a different market capitalization, but the service it currently provides in the larger market order would not be provided in the same way, if at all. Seen in this light, we can see how the larger market order expands its problem-solving abilities as different rule-bound orders are created within it and how these rule-bound orders create value for customers, employees and investors. The rule in the market order may be: If $A$ then $B$; the rule in other orders may be: If A then C, D, E, etc. It may be that the market throws up numerous failed orders before we get to set of rules that provide: If A then $\mathrm{Z}$; this then solves a problem in a way that customers really appreciate and will pay for.

\section{Tentative conclusions}

In this article we have repeated the, now commonplace, assertion that rule-following behavior occurs within organizations in both routine and non-routine, even unforeseen, situations. More novel, we have shown that the existence of rules and rule-following behavior can co-exist with hierarchy; that hierarchy can emerge naturally in groups following common rules. ${ }^{6}$ This may allow for a greater role for rule-following within the firm. However, nothing in this theory prevents firms from having a dual nature, being coordinated by command as well rule-following; a hierarchy, once in place, may achieve coordination using many different mechanisms-commands, goals, rules.

Beyond Hayek's insight into the division of knowledge in the larger market order and, by implication, within firms, Austrian

\footnotetext{
${ }^{6}$ This may also allow us to take a further step to resolving a controversy between Hayek and some of his critics. Both Rothbard $(2009,62)$ and Bruno Leoni (Leoni 1961, 99, 110; Hayek 1973, 168) criticized Hayek for his failure to distinguish between rules voluntarily committed to and rules imposed by a coercive authority. The conventional economic view has been to use the firm as an exemplar of the power of 'command' - perhaps the exact opposite is the case? If this were correct, the apparent tremendously effective coordinating power of 'command' in the firm would be seen as something different and there would be a different focus on the power of voluntary coordination in the larger market order. Or as Mary Parker Follett wrote of her insights into the law of the situation: "This gives, does it not, a slightly different aspect to the whole of business administration through the entire plant?" (Follett 1941, 59)
} 
insights into the firm have been relatively limited. It is submitted that this is because Austrian theorists of the firm have, following Hayek's lead, conflated hierarchy with coordination by 'command.' This has led some Austrian theorists to dismiss hierarchy and others to under-privilege rule-following. The purpose of this article has been to attempt to return Austrian theories of the firm to a realistic, hierarchical, but rule-based theory of the firm.

It may be that Hayek's core insights into the tremendous power of spontaneous orders and rule-following may have more general application than he envisaged. ${ }^{7}$ If so, Austrian insights into entrepreneurship, coordination and knowledge, have been under-appreciated in the conventional literature on the firm and management theory and practice.

\section{REFERENCES}

Aghion, Philippe, and Jean Tirole. 1997. "Formal and Real Authority in Organizations." Journal of Political Economy 105, no. 1: 1-29.

Alchian, Armen A., and Harold Demsetz. 1972. "Production, Information Costs and Economic Organization." American Economic Review 62, no. 5: 777-95.

Arrow, Kenneth J. 1974. The Limits of Organization. New York: W.W. Norton.

${ }^{7}$ Chester Barnard wrote to Mary Niles in a letter of 13 August 1956 after he had read her The Essence of Management:

I note one omission that surprises me. I did not find any quotation from Michael Polanyi nor is his name listed in the index, nor his writings in the bibliography. I think that his book The Logic of Liberty is one of the most important contributions to the theory of organization and management that I know, particularly relating to the limitations of the span of control and the necessity for autonomous behaviour in most organizations. If you don't know the book I can certainly recommend it most highly.' (Barnard 1956)

These late letters of Chester Barnard, to Hayek, Polanyi, de Jouvenal, etc., essentially restating firms as Polanyi-ish spontaneous orders are a hitherto un-investigated alternative to the Williamson explicit contrast between Barnardian hierarchical firms and Hayekian spontaneous orders (Williamson 2009). 
Barnard, Chester I. [1938] 1968. The Functions of the Executive, ed. K. Andrews. Harvard: Harvard University Press.

1956. Friedrich A. von Hayek papers. Letter to F A Hayek., Jan. 6. Box 61 folder 26/Box 72 Folder 18. New York: Hoover Institution Archive.

. 1956. Chester Barnard Collection. Hollis Number 602963, Box 2, Folder 39. Baker Library Historical Collections.

Becker, Markus C. 2004. "Organizational Routines: A Review of the Literature." Industrial and Corporate Change 13, no. 4: 643-78.

Biro, Dora. 2016. Interview, Jan. 28. A. Walsh, Interviewer.

Brady, Malcolm, and Aidan Walsh. 2008. "Setting Strategic Direction: A Top Down or Bottom Up Process." Business Strategy Series 9, no. 1: 5-11.

Bungay, Stephen. 2011. The Art of Action. London: Nicholas Brealey.

Bylund, Per L. 2016. The Problem of Production. A New Theory of the Firm. London: Routledge.

Caldwell, Bruce. 2004. Hayek's Challenge. Chicago: University of Chicago Press.

Casson, Mark. 1995. Entrepreneurship and Business Culture. Aldershot: Edward Elgar.

Coase, Ronald H. 1988. The Firm, the Market, and the Law. Chicago: University of Chicago Press.

Cowen, Tyler, and David Parker. 1997. Markets in the Firm: A Market-Process Approach to Management. London: Institute of Economic Affairs.

Creveld, Martin van. 1982. Fighting Power. Westport, Conn.: Greenwood Press.

Dopfer, Kurt. 2004. “The Economic Agent as Rule Maker and Rule User: Homo Sapiens Oeconomicus." Journal of Evolutionary Economics 14, no. 2: 177-95.

Engelke, Matthew. 2017. Think Like an Anthropologist. London: Pelican.

Evans-Pritchard, E. E. 1940. The Nuer. Oxford: Oxford at the Clarendon Press.

Flack, Andrea, Benjamin Pettit, Robin Freeman, Tim Guilford, and Dora Biro. 2012. "What Are Leaders Made Of? The Role of Individual Experience in Determining Leader-Follower Relations in Homing Pigeons." Animal Behaviour 83, no. 3: 703-09. 
Follett, Mary P. 1941. Dynamic Administration. The Collected Papers of Mary Parker Follett, ed. Henry C. Metcalf and Lyndall F. Urwick. New York: Harper and Brother.

Ford, Henry, and Samuel Crowther. 1923. My Life and Work. Whitefish, Mont.: Kessinger.

Foss, Nicolai J., and Peter G. Klein. 2012. Organizing Entrepreneurial Judgment. Cambridge: Cambridge University Press.

—. 2013. Hayek and Organizational Studies. In P. Adler, P. du Gay, G. Morgan, \& M. Reeds, Oxford Handbook of Sociology, Social Theory and Organizational Studies: Contemporary Currents. Oxford: Oxford University Press.

Gigerenzer, Gerd. 2007. Gut Feelings. London: Penguin Books.

Gigerenzer, Gerd, and Wolfgang Gaissmaier. 2011. "Heuristic Decision Making." Annual Review of Psychology 62, no. 1: 451-82.

Gladwell, Malcolm. 2011. “Creation Myth.” The New Yorker, May 16.

Grandori, Anna. 2002. "'Cognitive Failures' and Combinative Governance." Journal of Management and Governance 5, no. 3: 252-60.

Grant, Robert M. 1996. "Toward a Knowledge-Based Theory of the Firm." Strategic Management Journal 17, no. S2: 109-22.

Groysberg, Boris, Jesse Price, J., Jeremiah Lee, and J. Yo-Jud Cheng. 2018. "The Leader's Guide to Corporate Culture." Harvard Business Review 96, no. 1: 44-52.

Halder, F., O. Stapf, E. Rochricht, E., A. F. von Bechtolsheim, A. Zorbel, and H. Schultze. 1953. Analysis of US Field Service Regulations. United States Army, Europe, Historical Division, Headquarters. Frankfurt (Main): US Army.

Hayek, Friedrich A. 1948. Individualism and Economic Order. Chicago: University of Chicago Press.

__ [1952] 1972. The Sensory Order. Chicago: University of Chicago Press.

— 1960. The Constitution of Liberty. Chicago: University of Chicago Press. 1967. Studies in Philosophy, Politics and Economics. London: Routledge and Kegan Paul. 
1973. Law, Legislation and Liberty, vol I: Rules and Order. Chicago: University of Chicago Press.

. 1976. Law, Legislation and Liberty, vol II: The Mirage of Social Justice. Chicago: University ofChicago Press.

- 1979. Law, Legislation and Liberty, vol III: The Political Order of a Free People. Chicago: University of Chicago Press.

Heiner, Ronald A. 1983. "The Origins of Predictable Behavior." American Economic Review 73, no. 4: 560-95.

Hume, David. [1751] 1983. An Enquiry Concerning the Principles of Morals, ed. J. B. Schneewind. Indianapolis: Hackett.

Ioannidis, Stavros. 2003. "The Business Firm as a Hybrid Hayekian Order: What Is the Role of the Entrepreneur?" Pp. 153-71 in Advances in Austrian Economics, ed. Virgil Storr.

Jolles, Jolle W., Neeltje J. Boogert, Vivek H. Sridhar, Iain D. Couzin, and Andrea Manica. 2017. "Consistent individual differences drive collective behaviour and group functioning of schooling fish." Current Biology 27, no. 18: 2862-68.

Kahneman, Daniel. 2011. Thinking, Fast and Slow. London: Allen Lane.

Kirzner, Israel M. [1997] 2000. How Markets Work. London: IEA Hobart Paper 133.

Klein, Gary. 1998. Sources of Power: How People Make Decisions. London: MIT Press.

Kline, Bennett E., and Norman H. Martin. 1958. "Freedom, Authority, and Decentralization." Harvard Business Review 36, no. 3: 69-75.

Koch, Charles G. 2007. The Science of Success. How Market-Based Management Built the World's Largest Private Company. Hoboken, N.J.: John Wiley and Sons.

Langlois, Richard N. 1995. “Do Firms Plan?" Constitutional Political Economy 6, no. 3: 247-61.

Leoni, Bruno. 1961. Freedom and the Law, 3d ed.. Indianapolis: Liberty Fund.

Leube, Kurt R. 2003. Some Remarks on Hayek's The Sensory Order. Laissez-Faire 18, no. 2: 12-22. 
Loasby, Brian J. 1998. "The Organization of Capabilities." Journal of Economic Behavior and Organization 35, no. 2: 139-60.

- 2000. Connecting Principles, New Combinations, and Routines. Reflections Inspired by Schumpeter and Smith. Manchester: International Joseph A. Schumpeter Society.

March, James G. 1997. "Understanding How Decisions Happen in Organizations." In Organizational Decision Making, ed. Zur Shapira. Cambridge: Cambridge University Press.

Miller, Peter. 2010. The Smart Swarm. New York: Avery.

Moltke, Helmuth G. 1993. Moltke on the Art of War - Selected Writings, ed. D. J. Hughes, trans. D. J. Hughes, H. Bell. New York: Ballantine Books.

Nagy, Máté, Gábor Vásárhelyi, Benjamin Pettit, Isabella Roberts-Mariani, Tamás Vicsek, and Dora Biro. 2013. "Context-Dependent Hierarchies in Pigeons." Proceedings of the National Academy of Sciences 110, no. 32: 13049-54.

Nelson, Richard R., and Sidney G. Winter. 1982. An Evolutionary Theory of Economic Change. Cambridge, Mass.: Harvard University Press.

Pettit, Benjamin, Zsuzsa Akos, Tamás Vicsek, and Dora Biro. 2015. “Speed Determines Leadership and Leadership Determines Learning During Pigeon Flocking." Current Biology 25: 3132-37.

Polanyi, Michael. [1951] 1998. The Logic of Liberty. Indianapolis: Liberty Fund.

Pongracic, Ivan. 2009. Employees and Entrepreneurship. Cheltenham: Edward Elgar.

Quera, Vicenç, Francesc S. Beltran, and Ruth Dolado. 2010. "Flocking Behaviour: Agent-Based Simulation and Hierarchical Leadership." Journal of Artificial Societies and Social Simulation 13, no. 2: 8-27.

Reynolds, Craig W. 1987. "Flocks, Herds, and Schools: A Distributed Behavioral Model." Computer Graphics 21, no. 4: 25-34.

Roberts, John. 2004. The Modern Firm. Oxford: Oxford University Press.

Rothbard, Murray N. 2009. Rothbard vs The Philosophers, ed. Roberta A. Modugno. Auburn, Ala.: Ludwig von Mises Institute.

Rowe, Nicholas. 1989. Rules and Institutions. Hemel Hempstead: Philip Allan. 
Ruef, Martin. 2010. The Entrepreneurial Group. Princeton: Princeton University Press.

Samuels, Martin. 2013. "Doctrine for Orders and Decentralisation in the British and German Armies, 1885-1935." Unpublished.

Sautet, Frédéric E. 2000. An Entrepreneurial Theory of the Firm. London: Routledge.

Schlicht, Ekkehart. 1998. On Custom in the Economy. Oxford: Clarendon Press.

Smircich, Linda. 1983. "Concepts of Culture and Organizational Analysis." Administrative Science Quarterly 28, no. 3: 339-58.

Turner, J. C. (2005). "Explaining the Nature of Power: A Three-Process Theory." European Journal of Social Psychology 35, no. 1: 1-22.

United States Command and General Staff College. 2014. Auftragstaktik: The Basis for Modern Military Command. Pennyhill Press.

Vanberg, Viktor J. 1994. Rules and Choice in Economics. London: Routledge.

Walker, Paul. 2015. "The Past and Present of the Theory of the Firm: A Historical Survey of the Mainstream Approaches to the Firm in Economics." Available at SSRN: http://ssrn.com/abstract=2000431 or http://dx.doi.org/10.2139/ssrn.2000431.

Watts, Isobel, Máté Nagy, Theresa B. de Perera, and Dora Biro. 2016. "Misinformed Leaders Lose Influence over Pigeon Flocks." Biology Letters 12, no. 9: 544.

Weber, Max. [1968] 1978. Economy and Society, vol. 2, eds. G. Roth, C. Wittich. Berkeley: University of California Press.

Williamson, Oliver E. 2009. "Transaction Cost Economics: The Natural Progression." Nobel Prize Lecture. Retrieved March 1, 2015, from http:// www.nobelprize.org/nobel_prizes/economic-sciences/laureates/2009/ williamson_lecture.pdf

Witt, Ulrich. 2007. "Firms as Realizations of Entrepreneurial Visions." Journal of Management Studies 44, no. 7: 1125-40.

Wozniak, Steve, and Gina Smith. 2006. iWoz. New York: W.W. Norton.

Yu, Fu-Lai Tony. 2005. Firms, Strategies and Economic Change. Cheltenham: Edward Elgar. 